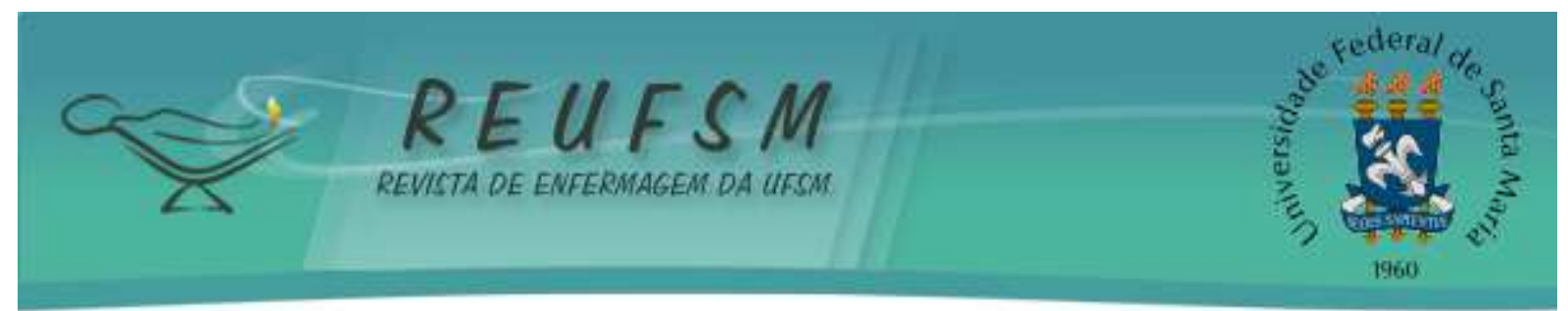

ARTIGO ORIGINAL

\title{
PERCEPÇÃO DAS PESSOAS EM SITUAÇÃO DE RUA SOBRE OS DETERMINANTES SOCIAIS DA SAÚDE
}

\section{HOMELESS PEOPLE'S PERCEPTION ABOUT THE SOCIAL DETERMINANTS OF HEALTH}

\section{PERCEPCIÓN DE LAS PERSONAS SIN HOGAR SOBRE LOS DETERMINANTES SOCIALES DE LA SALUD}

\author{
Maria Caroline das Chagas Winkelmann ${ }^{1}$ \\ Priscila Roberta Lopes $^{2}$ \\ Ivonete Teresinha Schülter Buss Heidemann ${ }^{3}$ \\ Gisele Cristina Manfrini Fernandes ${ }^{4}$ \\ Indiara Sartori Dalmolin ${ }^{5}$
}

\section{Doi: $10.5902 / 2179769227259$}

RESUMO: Objetivo: conhecer a percepção das pessoas em situação de rua sobre os determinantes sociais da saúde. Método: estudo descritivo, de abordagem qualitativa, realizado por meio de entrevistas semiestruturadas, com 15 partícipes do Sul do Brasil, em 2016. Os dados foram analisados a luz da análise temática. Resultados: os participantes abandonaram o convívio familiar e seus domicílios por situações conflituosas; pelo uso de drogas lícitas e ilícitas; pelo desemprego; e pela busca de liberdade. O vínculo familiar mostra-se fragilizado, com pouco ou nenhum contato com a família nuclear e ampliada. Conclusões: a percepção dos determinantes sociais das pessoas em situação de rua resulta do espaço em que habitam. Destaca-se com isso a necessidade eminente de se fortalecer políticas públicas, para que esta população conquiste o direito a saúde e transforme suas condições de vida.

Descritores: Determinantes sociais da saúde; Pessoas em situação de rua; Vulnerabilidade social; Enfermagem.

ABSTRACT: Aim: to know the perception of homeless people about the social determinants of health. Method: descriptive study with a qualitative approach, carried by means of semistructured interviews, with 15 homeless people from Southern Brazil, in 2016. The data were analyzed based on thematic analysis. Results: the homeless participants abandoned family life and their homes because of conflictive situations; by the use of licit and illicit drugs; unemployment; and the search for freedom. The family bond is fragile, with little or no contact with the nuclear and extended family. Conclusions: the perception of the social

\footnotetext{
1 Enfermeira. Hospital Infantil Joana de Gusmão (HIJG). Florianópolis, Santa Catarina, Brasil. E-mail: mariacaroline.chagas@hotmail.com

${ }^{2}$ Enfermeira. Graduação em Enfermagem. Universidade Federal de Santa Catarina (UFSC). Florianópolis, Santa Catarina, Brasil. E-mail: prilopes123@hotmail.com

${ }^{3}$ Enfermeira. Doutora em Enfermagem. Docente do Departamento de Enfermagem e do Programa de PósGraduação em Enfermagem (PEN) da UFSC. Florianópolis, Santa Catarina, Brasil. E-mail: ivoneteheideman@gmail.com

4 Enfermeira. Doutora em Enfermagem. Docente Adjunto do Departamento de Enfermagem da UFSC. Florianópolis, Santa Catarina, Brasil. E-mail: gisele.manfrini@ufsc.br

${ }^{5}$ Enfermeira. Mestre em Enfermagem. Doutoranda do PEN da UFSC. Docente Substituto do Instituto Federal de Educação, Ciência e Tecnologia de Santa Catarina (IFSC), campus Florianópolis. Florianópolis, Santa Catarina, Brasil. E-mail: indiarasartoridalmolin@gmail.com
} 


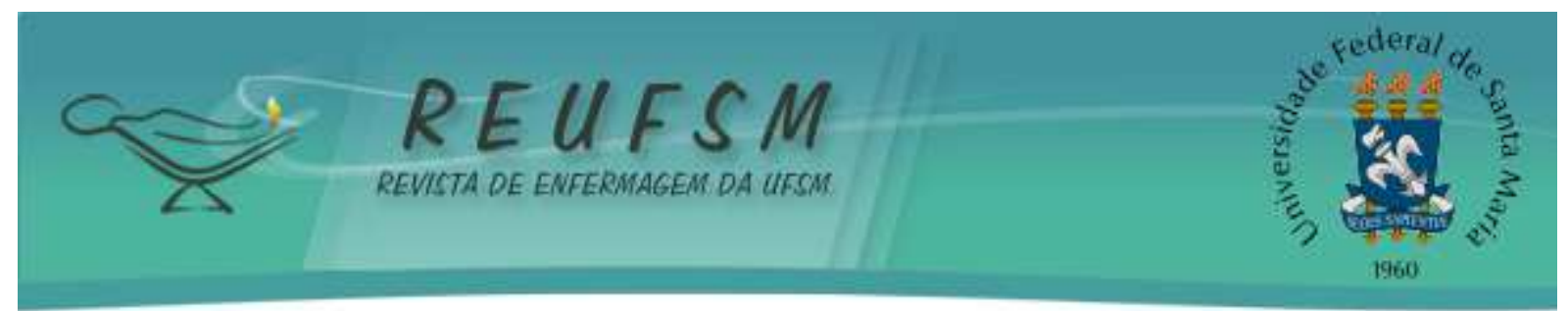

determinants of the homeless people results from the environment in which they live. This highlights the urgent need to strengthen public policies so that this population gains the right to health and changes its living conditions.

Descriptors: Social determinants of health; Homeless persons; Social vulnerability; Nursing.

RESUMEN: Objetivo: conocer la percepción de las personas sin hogar sobre los determinantes sociales de la salud. Método: estudio descriptivo, de carácter cualitativo, realizado por medio de entrevistas semiestructuradas, con 15 personas sin hogar del Sur de Brasil, en 2016. Los datos fueron analizados por medio de análisis temático. Resultados: los participantes abandonaron el convivio familiar y sus domicilios por situaciones conflictivas; por uso de drogas lícitas e ilícitas; por desempleo; y por búsqueda de libertad. El vínculo familiar se muestra fragilizado, con poco o ningún contacto con la familia nuclear y ampliada. Conclusiones: la percepción de los determinantes sociales de las personas sin hogar resulta del espacio en que habitan. Se destaca con ello la necesidad eminente de fortalecer políticas públicas, para que esa población conquiste el derecho a la salud y cambie sus condiciones de vida.

Descriptores: Determinantes sociales de la salud; Personas sin hogar; Vulnerabilidad social; Enfermería.

\section{INTRODUÇÃO}

As pessoas em situação de rua (PSR) correspondem a um grupo populacional que possui, coletivamente, algumas características: miséria extrema, vínculos familiares vulneráveis, falta de habitação e utilização dos logradouros públicos e das áreas destruídas como espaço de vivenda, de forma temporária ou permanente, bem como as unidades de alojamento para pernoite. ${ }^{1}$

Nos últimos anos, as PSR saíram do patamar de total invisibilidade social, sendo que alguns fatores contribuíram para isso como a criação da Política Nacional, que reconhece esses indivíduos como cidadãos, bem como a saúde como um direito humano. ${ }^{1}$

A Política Nacional para a População em Situação de Rua foi criada em 2009, por meio do decreto 7.053 e reforça as diretrizes previstas na Constituição Federal como a igualdade da assistência e o atendimento universalizado de acesso aos serviços de saúde. A política também preconiza o respeito a dignidade, garante o direito ao convívio em sociedade e familiar, valorizando e respeitando a vida e a cidadania do indivíduo independente da raça, idade, gênero e/ou condições sociais. ${ }^{2}$

Visa ainda a promoção dos direitos sociais e culturais da PSR, integrando os esforços não só do poder público, mas também da sociedade civil. Ademais, estimula que profissionais e gestores desenvolvam políticas destinadas a PSR e garante formação e capacitação permanente 


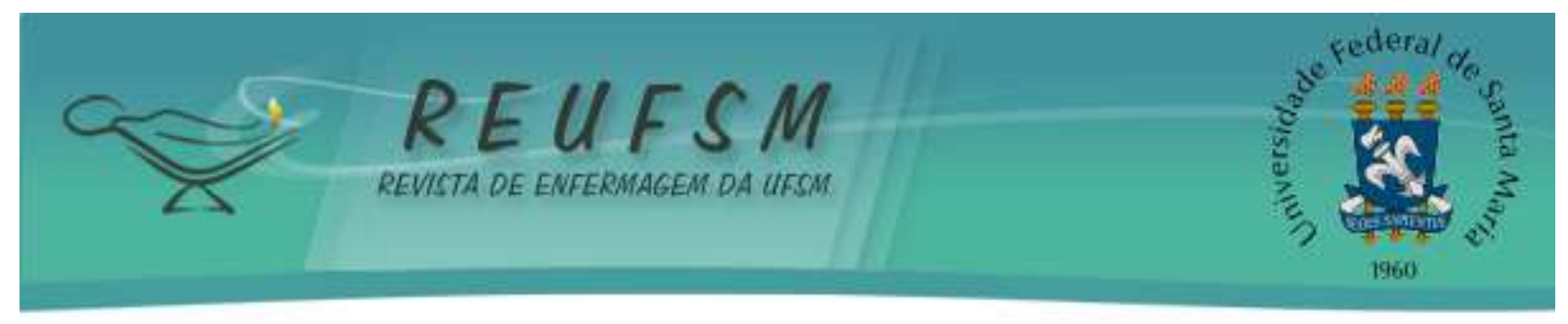

para que estes profissionais possam desenvolver ações para contribuir com a cultura de respeito, ética e solidariedade e com a convivência entre os demais grupos sociais e a PSR. ${ }^{2}$

O número avantajado de PSR no Brasil é decorrente do agravo de fatores sociais ao longo da história, como a acelerada urbanização no século XX, o êxodo rural, a concentração de pessoas nos grandes centros urbanos, o aumento das desigualdades sociais, pobreza e desemprego, além do preconceito e inexistência de políticas públicas. ${ }^{1}$

No município, onde a pesquisa foi desenvolvida, existem algumas ações voltadas as PSR por meio do Centro de Referência Especializado para População em Situação de Rua (Centro POP), que faz parte do Sistema Único de Assistência Social (SUAS). O Centro POP foi criado em 2010, está estruturado com uma equipe multiprofissional e realiza atendimento, encaminhamento e acompanhamento de usuários que o frequentam, disponibilizando três refeições diárias, acolhimento psicossocial individual e em grupo, local para higienização de roupas, auxílio na construção de currículo profissional, computadores com acesso a internet e possibilidade de usar o telefone.

O Centro POP realiza um serviço de abordagem social para acolher a demanda das ruas. Em média, esse serviço atende 120 pessoas por dia, sendo que 15 a 20 são atendidos por assistentes sociais e psicólogos, individualmente. O Centro POP auxilia nos contatos familiares, na busca por famílias e no deslocamento com passagens de ônibus municipal, intermunicipal e estadual sendo que, para isso, as pessoas precisam evidenciar o desejo de sair das ruas. Conta com uma equipe do Consultório na Rua (CnR), programa instituído pela Política Nacional de Atenção Básica, visando ampliar o acesso da população em situação de rua aos serviços de saúde. ${ }^{3}$

O CnR por sua vez é composto por equipes multiprofissionais que desenvolvem ações de saúde in loco ou de forma itinerante, conforme às necessidades dessa população. Apesar das equipes de CnR ser parte integrante da Rede de Atenção Psicossocial, poderá desenvolver ações com outros pontos da rede de atenção, como as Unidades Básicas de Saúde e o CAPS, conforme necessidades dos sujeitos. ${ }^{4}$

Nesse contexto, é importante conhecer os Determinantes Sociais da Saúde (DSS) e sua influência na vida da PSR, para compreender as razões que as levam a permanecer nestas condições e as estratégias de busca por condições e acesso à saúde. Os DSS representam as condições de vida e de trabalho, vinculadas com os aspectos de saúde dos indivíduos e 


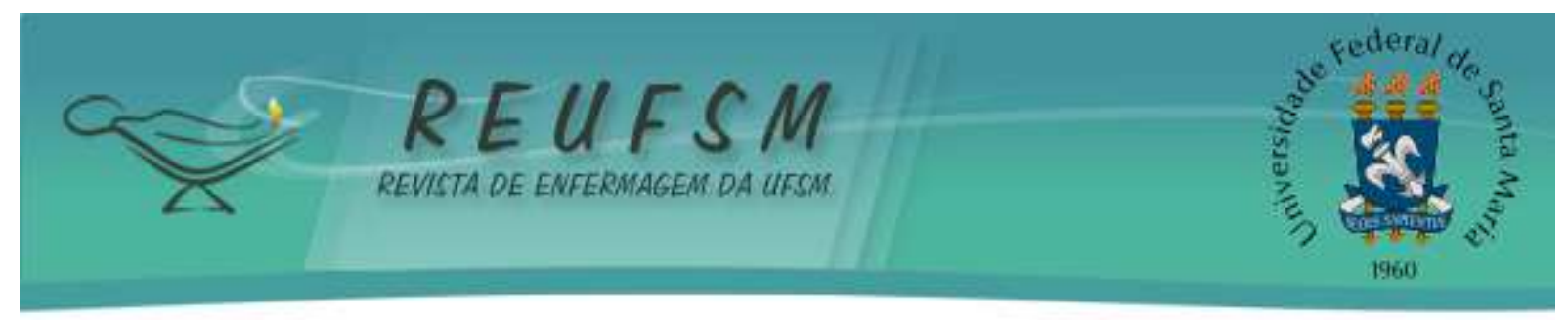

comunidades, estando intensamente ligados aos fatores comportamentais e estilos de vida da população. Dessa forma, os DSS constituem um apoio fundamental para a implantação das políticas de caráter transversal que buscam fortalecer a coesão e ampliar o empoderamento das comunidades vulneráveis, diminuindo as iniquidades sociais e ampliando a atuação intersetorial. ${ }^{5}$

Os DSS encontram-se no âmbito da promoção da saúde, à medida que consideram a saúde como produto de múltiplas influências, como qualidade de vida, padrão adequado de alimentação e sono, habitação e saneamento básico, boas condições de trabalho e modo de vida responsável. Desta forma, a falta dessas condições resulta na distribuição inadequada de renda existente no país. A desigualdade social revela a repartição desigual de poder, bens, serviços e renda, gerando uma falta de justiça natural que pode ser facilmente visível e imediata para certos grupos, especialmente as PSR. ${ }^{5}$

Diante disso, este estudo sustentou-se na seguinte questão: qual a percepção das PSR sobre os DSS? Para tanto, o objetivo foi conhecer a percepção das PSR sobre os DSS.

\section{MÉTODO}

Trata-se de uma pesquisa descritiva, de abordagem qualitativa. A coleta de dados foi realizada por meio de entrevista semiestruturada individual, gravada e transcrita na íntegra com duração de, aproximadamente, 30 minutos, no período de agosto a setembro de 2016. O instrumento foi composto por perguntas abertas sobre os DSS na vida das PSR. Antes de iniciar, o participante foi informado sobre o projeto e solicitado, após os esclarecimentos, a assinatura do Termo de Consentimento Livre e Esclarecido. Participaram do estudo 15 PSR da região Sul do Brasil, escolhidas de forma aleatória e convidadas a participar da pesquisa voluntariamente. Os critérios de inclusão foram faixa etária maior ou igual a 18 anos e se encontrar em situação de rua há seis meses ou mais, independente do sexo.

A definição do número de participantes do estudo foi estabelecida por meio do critério de saturação dos dados, isto é, um dispositivo de manejo das informações que prevê a explicação da chegada à saturação destas, alcançadas na prática, tornando-se uma técnica transparente ao leitor. ${ }^{6}$ Após a realização da pesquisa revelou-se a saturação de dados na décima terceira entrevista. Por meio dessa constatação foram realizadas mais duas investigações sem destaque de novos enunciados, encerrando-se no décimo quinto encontro a investigação. 


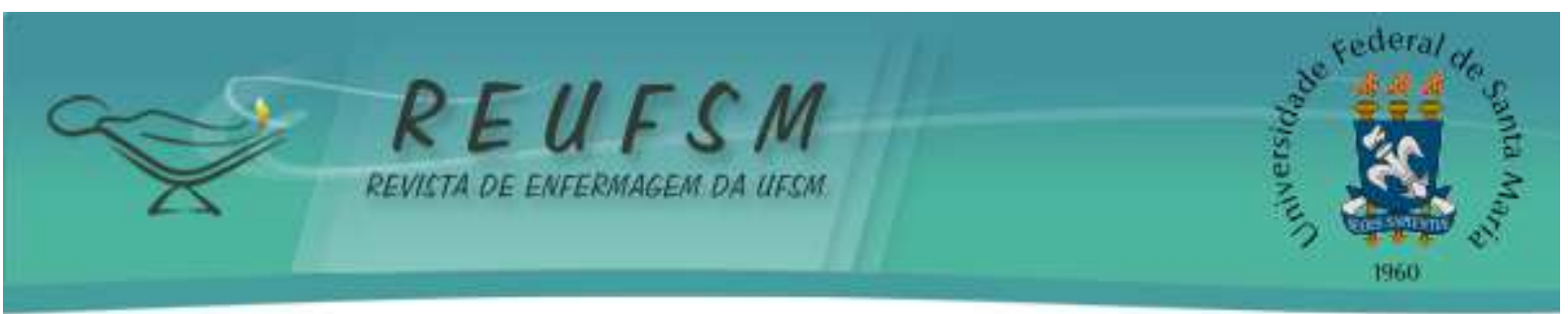

Para análise e interpretação dos dados utilizou-se a análise temática. ${ }^{7}$ Após a transcrição dos depoimentos, realizou-se a leitura do material por todos os pesquisadores envolvidos, iniciando a pré-análise e a exploração dos dados, os quais, posteriormente, foram agrupados em subcategorias temáticas e por último, categorizados.

Quanto aos aspectos éticos, o estudo respaldou-se na resolução 466/2012 ${ }^{8}$ e foi aprovado pelo Comitê de Ética em Pesquisa com Seres Humanos da Universidade Federal de Santa Catarina (CEPSH-UFSC), sob parecer $n^{\circ}$ 1.660.691, em 03 de agosto de 2016. Para garantir o anonimato das informações os participantes foram identificados pela letra $\mathrm{E}$ (referente a palavras entrevistado) seguida da numeração arábica que representou a sequência em que foram realizadas as entrevistas.

\section{RESULTADOS E DISCUSSÃO}

A título de caracterização demográfica da população participante entrevistada nesta pesquisa, elaborou-se a tabela 1 .

Tabela 1 - Caracterização das pessoas em situação de rua com relação aos aspectos demográficos.

\begin{tabular}{|c|c|c|c|c|c|}
\hline Idade & Sexo & Escolaridade & Estado civil & Filhos & $\begin{array}{l}\text { Tempo em que } \\
\text { esta na rua }\end{array}$ \\
\hline 37 & Feminino & $\begin{array}{l}\text { Ensino Fundamental } \\
\text { Incompleto }\end{array}$ & Casada & Sim & $1-2$ anos \\
\hline--- & Masculino & Ensino Superior & Solteiro & Sim & $1-2$ anos \\
\hline 62 & Masculino & --- & --- & Sim & $2-3$ anos \\
\hline 29 & Masculino & Ensino Médio & Solteiro & Não & 3-4 anos \\
\hline 47 & Masculino & Ensino Médio Incompleto & --- & Sim & $1-2$ anos \\
\hline 36 & Masculino & Ensino Médio & Solteiro & Sim & 2-3 anos \\
\hline 27 & Masculino & Ensino Médio Incompleto & Solteiro & Não & 1-2 anos \\
\hline 43 & Masculino & $\begin{array}{l}\text { Ensino Superior } \\
\text { Incompleto }\end{array}$ & Divorciado & Sim & 1-2 anos \\
\hline 57 & Masculino & $\begin{array}{l}\text { Ensino Superior } \\
\text { Incompleto }\end{array}$ & Solteiro & Sim & Mais de 5 anos \\
\hline 43 & Masculino & $\begin{array}{l}\text { Ensino Superior } \\
\text { Incompleto }\end{array}$ & Solteiro & Sim & 6 meses - 1 ano \\
\hline 27 & Masculino & $\begin{array}{l}\text { Ensino Superior } \\
\text { Incompleto }\end{array}$ & Solteiro & Não & 1-2 anos \\
\hline 39 & Masculino & Ensino Fundamental & --- & Sim & 6 meses \\
\hline 45 & Masculino & Ensino Médio Incompleto & Divorciado & Sim & 6 meses -1 ano \\
\hline 40 & Masculino & $\begin{array}{l}\text { Ensino Fundamental } \\
\text { Incompleto }\end{array}$ & Solteiro & Sim & $1-2$ anos \\
\hline 54 & Masculino & $\begin{array}{l}\text { Ensino Fundamental } \\
\text { Incompleto }\end{array}$ & Solteiro & Sim & Mais de 5 anos \\
\hline
\end{tabular}




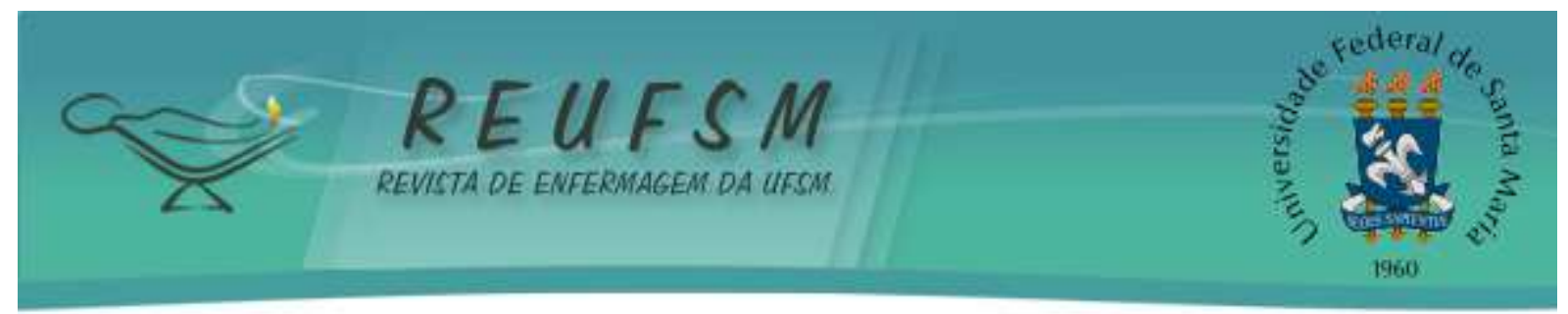

Com relação aos determinantes de idade, sexo e estado civil, pode-se identificar que em sua maioria as PSR entrevistadas foram homens, solteiros, na faixa etária entre 24 a 60 anos. Predominaram PSR que tiveram algum filho. O tempo de permanência na rua entre os entrevistados variou de 1 a 4 anos, em sua maioria. Um dado interessante é a escolaridade que alternou entre pessoas com ensino fundamental, médio e superior completo ou incompleto. Salienta-se que a caracterização da população de rua estudada contribui para a compreensão da relação com os determinantes sociais abordados na análise dos dados no presente estudo.

Assim como o comportamento e os estilos de vida pessoais. A posição social do indivíduo é determinada por um dado contexto social, que por sua vez, provoca diferenças nos níveis de saúde, como exposição diferente a riscos variados e, considerando que cada pessoa, uma vez tendo sido exposta, possui uma vulnerabilidade e uma reação específica a esses riscos, as consequências sociais e físicas serão diferentes ao se contrair uma doença. ${ }^{9-10}$

As PSR ocupam uma posição social diferenciada do restante das pessoas, encontrando-se mais exposta a riscos que causam danos à saúde, principalmente em relação a violência. Constitui-se de uma população heterogênea que possuem, em comum, a sobrevivência por meio de atividades produtivas desenvolvidas na rua. As causas desta realidade são diversas como, por exemplo, urbanização, globalização; desigualdade social; pobreza; desemprego; ausência de moradia; individualismo, isolamento social; transtornos mentais; e uso abusivo de álcool e outras drogas. ${ }^{11}$

A partir da operacionalização da análise temática, chegou-se a três categorias: Pessoas em Situação de Rua: motivos que levaram a morar na rua; Pessoas em Situação de Rua: e o contexto das drogas lícitas e ilícitas; e Relações familiares na realidade de quem vive nas ruas.

\section{Pessoas em Situação de Rua: motivos que levaram a morar na rua}

São vários os motivos que levam as pessoas a mudarem para as ruas, algumas por opção, outras buscam a rua um abrigo para sobreviver. Os indivíduos que escolheram voluntariamente as ruas, parecem ter uma adaptação facilitada neste ambiente. Esses relatam estar buscando liberdade, na maioria dos casos. Assim, veem as ruas como uma forma para alcançarem seus objetivos ao saírem do domicílio formal. ${ }^{12}$

Quando questionados sobre os motivos que os levaram a morar nas ruas, dos 15 entrevistados, seis responderam que moram na rua pela existência de conflitos familiares, tanto relacionados à família nuclear, como com a família ampliada. 


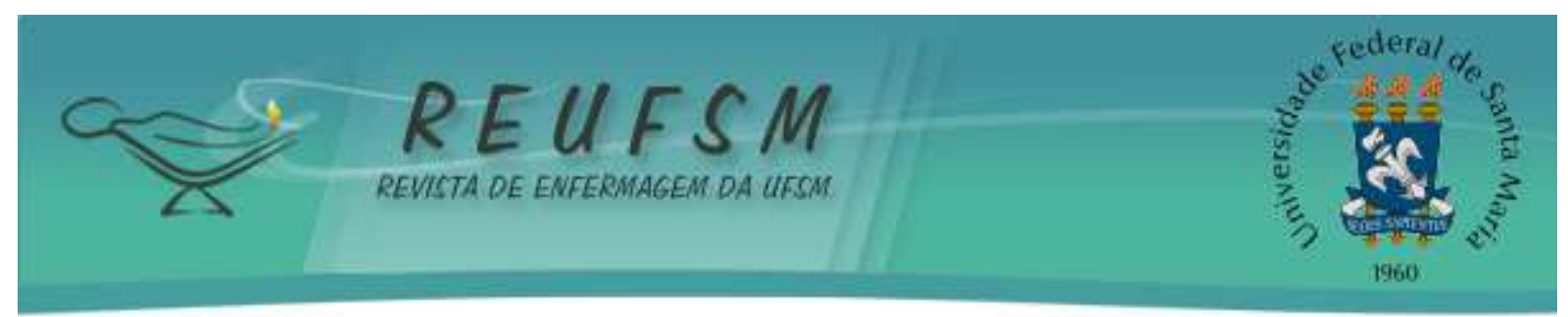

Certo dia eu fui obrigado a dizer pra ela, próximo dia que a gente se separar vou-me embora que você nunca mais vai me ver. E aconteceu. Me separei num sábado a noite e no sábado a noite mesmo eu saí, e até hoje ela não tem notícia de mim, e nem eu tenho notícia dela, não tenho noticia das minhas filhas. (E15)

Estudo explicita três razões que condicionam a PSR a estar nesta situação, sendo elas: a ruptura com os vínculos familiares, a falta de condições materiais e financeiras, como o desemprego e a dependência do álcool e das outras drogas. ${ }^{13}$ A família tem importante papel neste contexto, visto ser ela um local de socialização e de cuidado, proporcionando valores, apoio emocional e ações promotoras de saúde para seus integrantes. Sendo assim, existe a ideia de que a família quando fragilizada pode colaborar com afastamento dos seus membros como as PSR sofreram. ${ }^{14}$

Os DSS são importantes influentes da saúde dessas pessoas, à medida que se pautam em justificativas epidemiológicas, voltadas para a compreensão do impacto da desigualdade na saúde e bem-estar social, situado no papel da política de redução da desigualdade, se distanciando do discurso tradicional da saúde que se pauta no indivíduo. Neste sentido, o direito à saúde, o acesso às condições de saúde é um dos principais DSS. ${ }^{15-16}$

Três PSR afirmaram que estão desempregadas, expressando as dificuldades dessa condição perante a sociedade, bem como o seu aspecto condicionante de persistir na situação de rua.

Por que eu estou sem emprego e procuro todo dia, e não estou conseguindo emprego. Estive em duas empresas de marcenaria, fiz o teste prático, o dono gostou do meu acabamento, mas quando eu disse que estava em situação de rua, ele disse depois eu ligo pra você, não liga, é complicado. (E13)

Outro participante mencionou que mora na rua por falência financeira.

Foi falência financeira em 2014, eu trabalhava em um restaurante e eu estava cheio de dívidas, eu tive que vender tudo que eu tinha dentro do meu apartamento e sair fora pra poder quitar todos os aluguéis, os aluguéis estavam atrasados. (E2)

Apenas um dos entrevistados respondeu que mora na rua por vontade própria, por escolha.

Eu moro na rua por opção. (E9)

Corroborando com os dados da pesquisa, ressalta-se o fato de muitas pessoas estarem nas ruas por buscar liberdade, por interromper vínculos familiares e afetivos, pela falta de condições financeiras, por decepções e tristeza ou para quebrar regras impostas pela sociedade. Além de que, a rua oferecer facilidades ao uso e abuso de álcool e outras drogas, do vício em jogos de azar, ou ainda por vontade própria. ${ }^{17}$ 


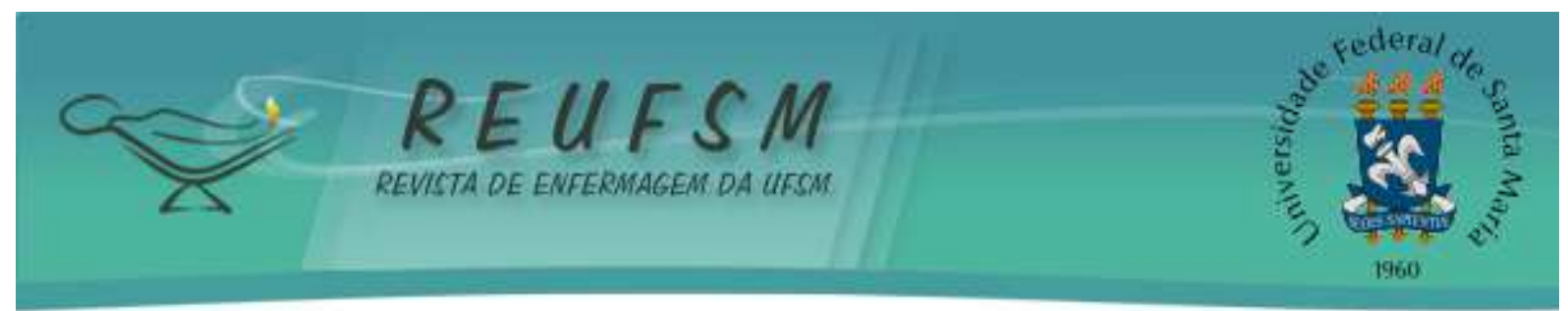

A PSR, muitas vezes, tem sua vida confinada a lugares públicos, não sendo protegidos por tetos e pelas paredes de uma casa. Uma investigação realizada no Canadá evidenciou que as PSR desejavam ter um espaço próprio, onde pudessem ter contato com seus objetos e utensílios domésticos, com higiene, privacidade e estabilidade. ${ }^{16}$ A falta de demarcação dos territórios familiares gera dificuldades, como a constante insegurança e problemas para guardar os bens materiais. ${ }^{11}$

\section{Pessoas em Situação de Rua: e o contexto das drogas lícitas e ilícitas}

As dificuldades das condições de vida na rua se agravam ainda mais nos usuários compulsivos, pois sua prioridade é o acesso à droga. Qualquer dinheiro ou pertence torna-se droga ilícita, as quais compõem as substancias químicas ou composto químico natural ou artificial proibido. $^{18}$

Ao serem questionados sobre a utilização de drogas, dos 15 entrevistados cinco não utilizam drogas lícitas e ilícitas e relatam o mal que as drogas trazem para a sociedade, conforme a fala:

Não uso drogas, a droga leva pro fundo do poço, ela te faz roubar, faz matar, droga não tem outro caminho. (E2)

Outros cinco relatam fazer uso de álcool.

Eu só uso álcool mesmo. Não fumo, não uso drogas só negocio de bebida. Eu uso álcool porque eu gosto. (E15)

A reabilitação ou tratamento do álcool e outras drogas é uma tarefa difícil, são vários os empecilhos encontrados nesse caminho, na maioria das vezes, após uma internação, as pessoas acabam voltando para o ambiente onde começaram a usar, encontram as antigas amizades e retornam a utilização. Desta forma, é reforçada a necessidade de criação de vínculo entre o usuário e o serviço de saúde, de forma a aumentar a aceitação do tratamento. A droga é vista pelos usuários como uma doença que, para ser superada, é preciso muita força de vontade. ${ }^{19}$

Ademais, três PSR se identificaram como ex-usuários de drogas e relacionam o uso com o fato de estar na rua.

Agora eu dei um tempo, mas até uns seis meses atrás, eu tava num crack desgraçado. A droga tem tudo a ver com a rua, muita gente ta na rua por causa da droga, família de drogado não vai aceitar, um pai não aceita um drogado dentro de casa. (E12)

Dos 15 entrevistados, três admitiram fazer uso de drogas cotidianamente. 


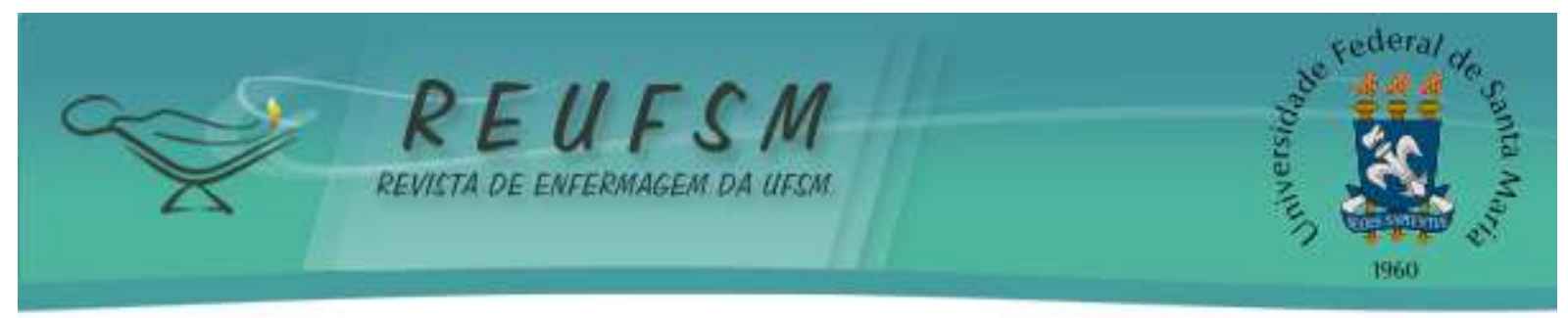

Quando eu uso, eu uso pra me esconder, pra ficar quieto no meu canto, isolado, porque eu sinto muita falta da minha família, da minha mulher, da minha filha. (E5)

Eu usei todos os tipos de drogas, que você não pode imaginar. Eu comecei a usar drogas com 12 anos de idade, foram 27 anos usando drogas. (E10)

A dependência de drogas ilícitas e o consumo incontrolado de álcool são razões que levam as pessoas a procurar as ruas, que lhes permitem viver em ambiente diferente e abandonar as regras e autoritarismos impostos pelos familiares e pela sociedade, para mudar suas rotinas e adquirir liberdade. ${ }^{17}$

Em contrapartida, um estudo realizado com PSR revelou que não existe diferenças significativas entre as mulheres que vivenciam dias sem-teto versus aquelas alojadas de forma contínua, pois deve ocorrer alta motivação para mudar o consumo de álcool ou drogas. ${ }^{20}$

O usuário de droga corrompe sua vida à medida que aumenta a possibilidade de utilização de uma variedade maior de drogas. Muitos usuários iniciam com a maconha, evoluindo para a cocaína, sendo utilizada de várias maneiras, até chegarem ao crack, onde admitem ter perdido tudo o que tinham por causa da droga, levando-os a decadência financeira, física e emocional. ${ }^{18}$

O uso de drogas foi um DSS nesse estudo e balizou um dos motivos pela perda do contato familiar.

Fazia dois anos que não falava mais com minha família por que eu achava que eles estavam brigados comigo, essas coisas, porque eu vendi o celular, tu sabe como que é essas coisas de dependente. Eu venho batalhando a um tempo já com o vício, complicado, não é fácil sabe. (E6)

Não tenho contato com ninguém da minha família. Celular eu troquei por droga, daí já era, fiquei sem o contato de ninguém. (E12)

$\mathrm{O}$ uso de qualquer substância psicoativa é um fator que desencadeia relações familiares interrompidas ou fragilizadas. Não se pode depositar toda a responsabilidade na família pela conduta dos seus indivíduos, pois outras condições também influenciam na inicialização no consumo das drogas como fatores econômicos, sociais e culturais. ${ }^{14}$

Quatro dos entrevistados relataram que foram morar na rua por serem usuário de drogas.

Por causa que eu uso drogas entendeu?! Eu uso crack. Eu saí de casa pra minha mãe não sofrer, é pra ela não ficar brigando. (E4) 


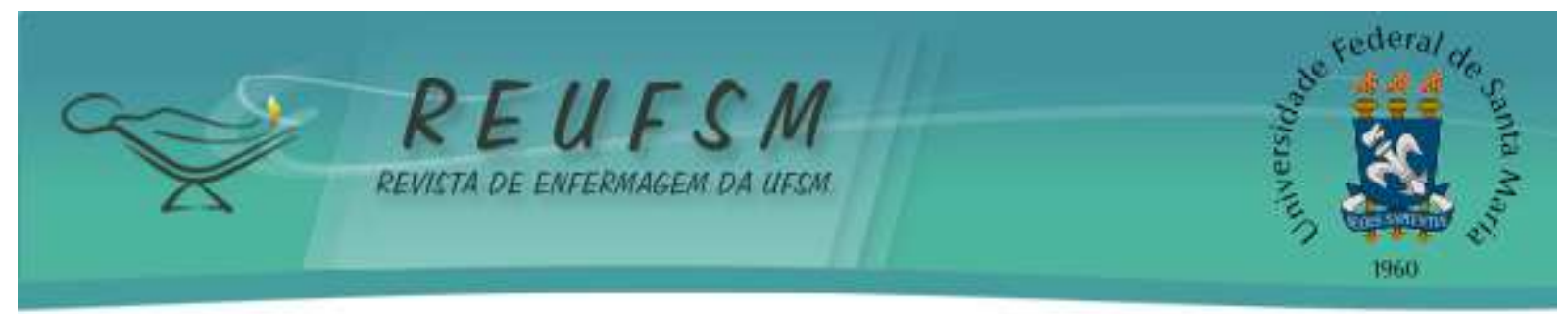

Por esta população ser diretamente afetada pela violência, pelas limpezas urbanas e por se afastarem de suas relações e vínculos familiares, enfrentam obstáculos diários para a sobrevivência. A situação da miséria e de falta de moradia está envolvida com a dependência química e a criminalidade. ${ }^{21} \mathrm{O}$ estudo revelou algumas particularidades e determinantes sociais envolvidos no fenômeno da PSR, como a dependência química. É fundamental trabalhar a equidade de acesso a esta população em vulnerabilidade social para diminuir o uso de drogas e suas consequências.

Com base nesses dados e discussões, percebe-se que as PSR estão inseridas em um contexto favorável ao uso de drogas lícitas e ilícitas, seja por fatores pessoais ou coletivos, o que interfere, diretamente, nas condições de vida e saúde. Para tanto, o conhecimento da realidade e necessidades das PSR por parte da sociedade civil, dos serviços de saúde, assitência social e segurança pública é imprescindível para a efetivação das políticas públicas voltadas a este grupo populacional, priorizando o acolhimento, a compreensão e intervenção sobre os DSS, trabalhando em prol de ações intersetoriais efetivas e inclusivas.

\section{Relações familiares na realidade de quem vive nas ruas}

Ao adotar a rua como abrigo, a relação familiar pode passar por mudanças. Quando questionados sobre o contato e vínculo com suas famílias, oito afirmam preservar relações com seus familiares, destes um recebe auxilio da família e um contribui com a renda familiar.

Eu tive contato com minha família no sábado, há três dias. Liguei pra minha irmã que mora aqui e liguei pra minha irmã que mora no Rio Grande do Sul. (E10)

Falo com eles diariamente, o dia que não falo com meus filhos não é um bom dia. (E13)

Os vínculos sociais e as relações de ajuda e confiança entre pessoas e grupos são essenciais para a promoção e proteção da saúde individual e coletiva. Assim se incluem políticas que aspiram constituir redes de apoio e fortalecer a participação das pessoas e das comunidades, especialmente dos grupos vulneráveis, com ações coletivas e com discussões interdisciplinares e intersetoriais, para subsidiar a melhoria de suas condições de saúde e bem-estar. ${ }^{22}$

A unidade familiar possui grande importância na dinâmica do processo saúde-doença, e, devido a isso, muitas políticas públicas são voltadas para programas de atenção à saúde que buscam recolocar a unidade familiar em uma posição de responsabilidade pelo cuidado de 


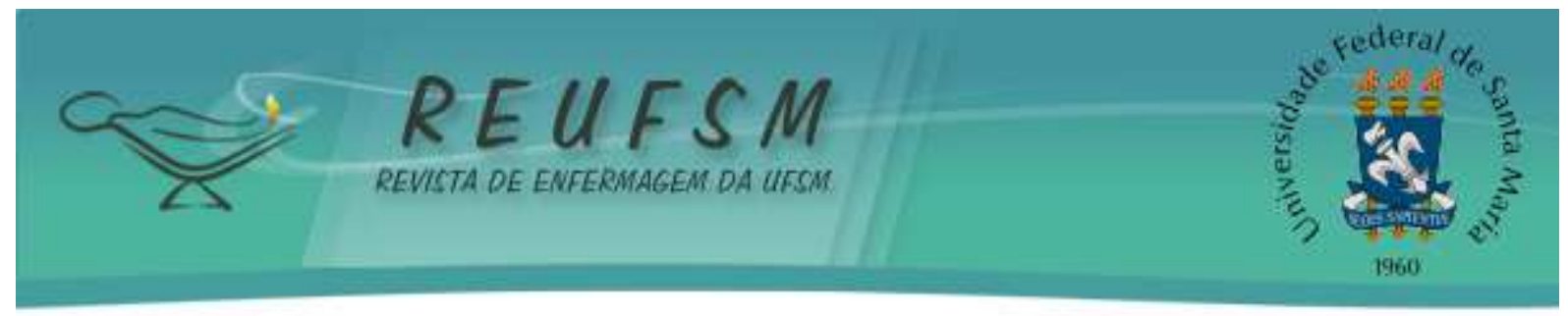

seus membros. ${ }^{23}$ Em contrapartida, as PSR por sua dinâmica de vida mostram-se, muitas vezes, sem contato com seus familiares, conforme as falas:

do meu pai eu perdi o contato quando roubaram meu celular, e hoje não tem como achar. É que assim, eu não quero passar meus problemas para a minha família. (E2)

não tenho contato. E nem quero ter. (E9)

o irmão que eu tenho por parte de mãe mora no norte da cidade, o contato é raro, depois que vim pra rua eu me larguei. (E14)

eles não sabem se eu estou vivo, se estou morto. Faz muitos anos que não falo com ninguém. (E15)

Conhecer as relações familiares que modificam e interferem nas capacidades e expressões de sentimentos das pessoas que vivem nas ruas é importante para evidenciar fatores que não foram compreendidos ou investigados. Também para destacar se existe ou não a interrelação entre PSR e familiares e estar atento para identificar o impacto dessa relação no seu modo de vida. Reconhecer as individualidades pessoais de cada membro dentro do universo da família, a partir das suas crenças, culturas e dinâmicas de vida, é importante, sabendo que ela é o eixo fundamental para a construção da cidadania e do respeito aos direitos humanos. ${ }^{23}$

\section{CONCLUSÕES}

Pesquisar os DSS que influenciam o processo de vida das PSR, expostas a constante vulnerabilidade social, foi imprescindível para ampliar as possibilidades de ações e políticas voltadas a esse grupo populacional respondendo, dessa forma, ao objetivo proposto.

São vários os DSS que influenciam a vida da PSR encontrados no estudo, dentre os quais foram abordados, a família e as redes de apoio social. Neste contexto, considera-se importante dar visibilidade para essa população, unindo esforços intersetoriais para a melhoria das condições de vida e saúde, investindo em políticas públicas, profissionais qualificados e educação social para uma cultura de paz.

Como limites, destacam-se o caráter local e as dificuldades para a realização da coleta de dados, em virtude do espaço das ruas apresentar ruídos, intempéries e as PSR possuírem uma dinâmica espacial extremamente mutante. Todavia, pesquisar no contexto real de vida dos indivíduos foi transformador, expandindo a compreensão sobre o viver/estar na rua. 


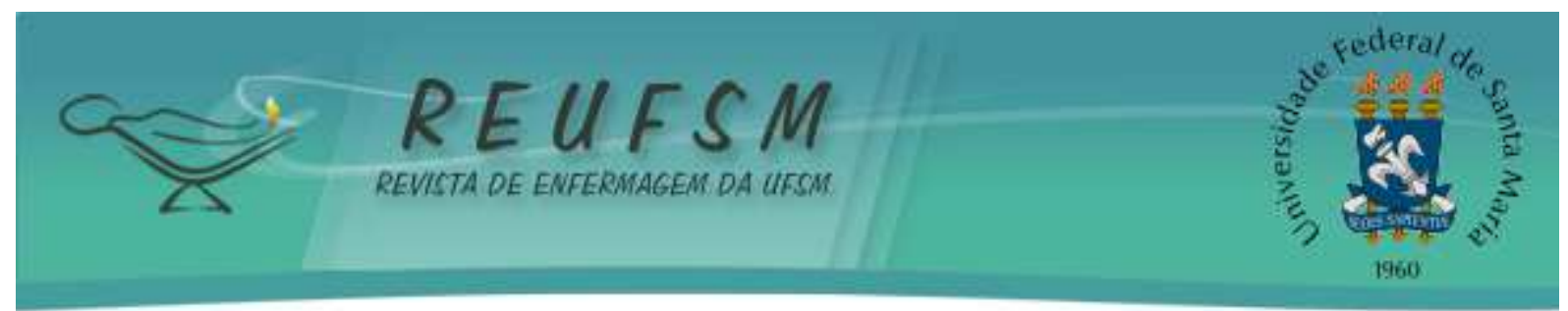

Com isso, conclui-se que alguns elementos possibilitam a saúde das PSR como o apoio do Centro de Referência Especializado para População em Situação de Rua - Centro POP, que viabiliza a distribuição de alimentos, higienização e apoio psicossocial para essas pessoas. Urge a realização de pesquisas com esses indivíduos, buscando compreendê-los como cidadãos, pois mesmo sem um domicílio fixo, é imprescindível o respeito pela sua condição de vida e cabe à academia a produção de conhecimentos que contribuam para a construção de uma sociedade mais justa, com acesso e garantia de condições de saúde às PSR.

\section{REFERÊNCIAS}

1. Brasil. Ministério da Saúde. Secretaria de Gestão Estratégica e Participativa. Departamento de Apoio à Gestão Participativa. Saúde da população em situação de rua: um direito humano. Brasília (DF); Ministério da Saúde; 2014.

2. Brasil. Presidência da República. Decreto no 7.053 de 23 de dezembro de 2009. Institui a Política Nacional para a População em Situação de Rua e seu Comitê Intersetorial de Acompanhamento e Monitoramento e dá outras providências. Brasília (DF); Ministério da Saúde; 2009.

3. Brasil. Ministério da Saúde. Secretaria de Atenção à Saúde. Departamento de Atenção Básica. Política Nacional de Atenção Básica (PNAB). Brasília (DF); Ministério da Saúde; 2012.

4. Ferreira CPS, Rozendo CA, Melo GB. Consultório na Rua em uma capital do nordeste brasileiro: o olhar de pessoas em situação de vulnerabilidade social. Cad Saúde Pública [Internet]. 2016 [acesso em 2018 mar 11];32(8):1-10. Disponível em: http://www.scielo.br/pdf/csp/v32n8/1678-4464-csp-32-08-e00070515.pdf.

5. Pereira ADS, Soares DKM, Oliveira KKAD, Marques LDA, Moreira DP, Vieira LJEDS. Análise da produção científica sobre os determinantes sociais da saúde. Cadernos ESP [Internet]. 2013 [acesso em 2017 jun 23];7(2):40-52. Disponível em: http://www.esp.ce.gov.br/cadernosesp/index.php/cadernosesp/article/view/113/82.

6. Fontanella BJB, Luchesi BM, Saidel MGB, Ricas J, Turato ER, Melo DG. Amostragem em pesquisas qualitativas: proposta de procedimentos para constatar saturação teórica. Cad Saúde Pública [Internet]. 2011 [acesso em 2018 mar 08];27(2):389-94. Disponível em: http://www.scielo.br/pdf/csp/v27n2/20.pdf.

7. Minayo MCDS. O desafio do conhecimento: pesquisa qualitativa em saúde. São Paulo: Hucitec; 2014.

8. Brasil. Ministério da Saúde. Conselho Nacional de Saúde. Resolução no 466, de 12 de dezembro de 2012. Aprovar as seguintes diretrizes e normas regulamentadoras de pesquisas envolvendo seres humanos. Brasília (DF); Ministério da Saúde; 2012.

9. Buss PM, Pellegrini Filho A. Saúde e seus determinantes sociais. Physis [Internet]. 2007 [acesso em 2017 jun 23];17(1):77-93. Disponível em: http://www.scielo.br/pdf/physis/v17n1/v17n1a06.pdf. 


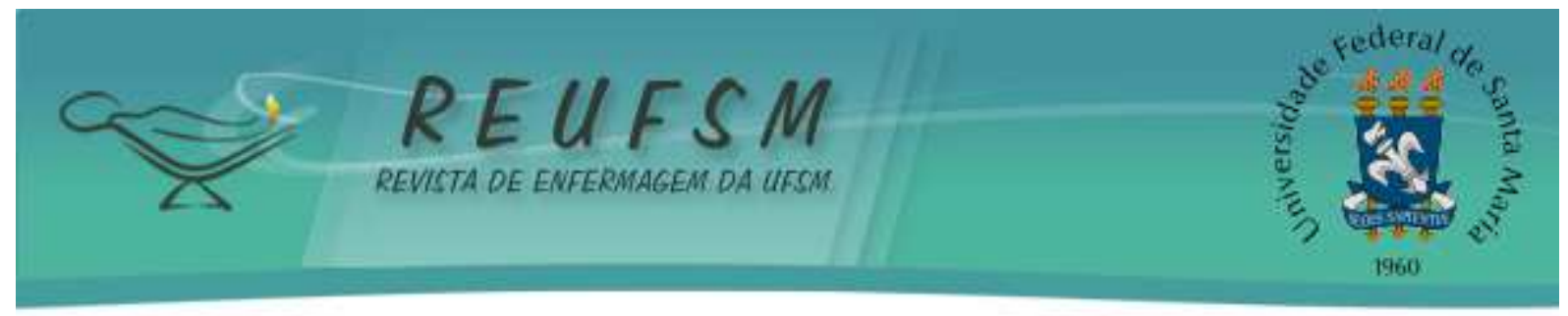

10. Santos JLGD, Vieira M, Assuiti LFC, Gomes D, Meirelles BHS, Santos SMDAD. Risco e vulnerabilidade nas práticas dos profissionais de saúde. Rev Gaúcha Enferm [Internet]. 2012 [acesso em 2017 jun 23];33(2):205-12. Disponível em: http://www.scielo.br/pdf/rgenf/v33n2/28.pdf.

11. Oliveira R, Sampaio SS, Souza AJM. População de rua e direito à moradia: uma análise a partir do Programa Minha Casa Minha Vida. Soc Debate [Internet]. 2017 [acesso em 2018 mar 11];23(1):180-200. Disponível em: http://www.rle.ucpel.tche.br/index.php/rsd/article/view/1508/1012.

12. Andrade LP, Costa SLD, Marquetti FC. A rua tem um ímã, acho que é a liberdade: potência, sofrimento e estratégias de vida entre moradores de rua na cidade de Santos, no litoral do Estado de São Paulo. Saude Soc [Internet]. 2014 [acesso em 2017 jun 23];23(4):1248-61. Disponível em: http://www.scielo.br/pdf/sausoc/v23n4/0104-1290-sausoc23-4-1248.pdf.

13. Lima CM, Oliveira JOSD. Participação popular dos moradores de rua na gestão pública do município de Porto Alegre, RS. Rev Univap [Internet]. 2012 [acesso em 2017 jun 23];18(32):161-72. Disponível em: http://revista.univap.br/index.php/revistaunivap/article/view/60/123.

14. Caravaca-Morera JA, Padilha MI. A dinâmica das relações familiares de moradores de rua usuários de crack. Saúde Debate [Internet]. 2015 [acesso em 2018 mar 11];39(106):748-59. Disponível em: http://www.scielo.br/pdf/sdeb/v39n106/0103-1104-sdeb-39-106-00748.pdf.

15. Sotero M. Vulnerabilidade e vulneração: população de rua, uma questão ética. Rev Bioética [Internet]. 2011 [acesso em 2017 jun 23];19(3):799-817. Disponível em: http://revistabioetica.cfm.org.br/index.php/revista_bioetica/article/view/677/709.

16. Perreault M, Carvalho ERD, Barros FPCD. O direito à saúde como um dos principais determinantes sociais da saúde. Rev Enferm UFSM [Internet]. 2013 [acesso em 2018 mar 09];4(Esp.):719-28. Disponível em: https://periodicos.ufsm.br/reufsm/article/view/13854/pdf.

17. González MA, Blandón D, Quiceno JA, Giraldo Á, Forero C. Habitar bajo los puentes: vida y muerte; dos formas de comenzar algo. Rev Fac Nac Salud Pública [Internet]. 2014 [acesso em 2017 jun 23];32(2):36-41. Disponível em: http://www.scielo.org.co/pdf/rfnsp/v32n2/v32n2a05.pdf.

18. Raupp L, Adorno RDCF. Territórios psicotrópicos na região central da cidade de Porto Alegre, RS, Brasil. Saúde Soc [Internet]. 2015 [acesso em 2017 jun 23];24(3):803-15. Disponível em: http://www.scielo.br/pdf/sausoc/v24n3/0104-1290-sausoc-24-03-00803.pdf.

19. Gabatz RIB, Johann M, Terra MG, Padoin SMM, Silva AA, Brum JL. Percepção do usuário sobre a droga em sua vida. Esc Anna Nery [Internet]. 2013 [acesso em 2017 jun 23];17(3):5205. Disponível em: http://www.scielo.br/pdf/ean/v17n3/1414-8145-ean-17-03-0520.pdf.

20. Upshur CC, Weinreb L, Cheng DM, Kim TW, Samet JH, Saitzr R. Does experiencing homelessness affect women's motivation to change alcohol or drug use? Am J Addict [Internet]. 2014 [acesso em 2018 mar 09];23(1):76-83. Disponível em: https://www.ncbi.nlm.nih.gov/pubmed/24313245. 


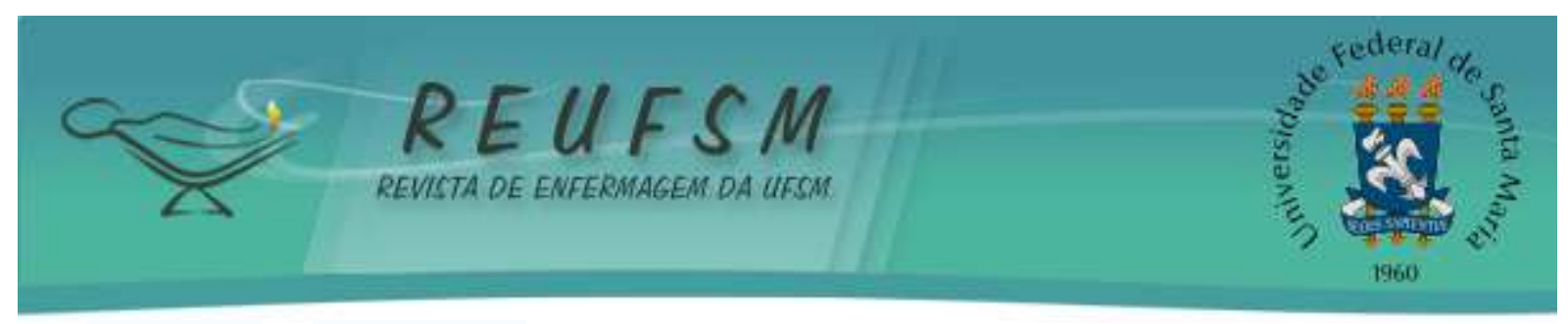

21. Santana VSD, Castelar M. População em situação de rua e a luta pela cidadania. Rev Baiana Saúde Pública [Internet]. 2014 [acesso em 2017 jun 23];38(2):357-69. Disponível em: https://www.researchgate.net/publication/273899625_A_populacao_em_situacao_de_rua_e_a _luta_pela_cidadania.

22. Lettiere A, Nakano AMS. Domestic violence: possibilities and limitations in coping. Rev Latinoam Enferm [Internet]. 2011 [acesso em 2017 jun 23];19(6):1421-8. Disponível em: http://www.scielo.br/pdf/rlae/v19n6/20.pdf.

23. Elsen I, Marcon SS, Souza AIJD, Nitschke RG, organizadoras. Enfermagem com famílias: modos de pensar e maneiras de cuidar em diversos cenários brasileiros. Florianópolis: Editora Papa Livro; 2016.

Data de submissão: 21/05/2017

Data de aceite: 19/03/2018

Autor correspondente: Indiara Sartori Dalmolin

Email: indiarasartoridalmolin@gmail.com

Endereço: Rua Sabino Anísio da Silveira, no 291, Campeche, Florianópolis, Santa Catarina, Brasil

CEP: 88065033 